\title{
New voltage sag detection based on phase angle analysis for the new topology of voltage sag compensator
}

\author{
Nasrudin Abd. Rahim ${ }^{1}$ and Muhamad Mansor ${ }^{2 a)}$ \\ ${ }^{1}$ Dept. of Electrical Engineering, Faculty of Engineering, University of Malaya, \\ 50603 Kuala Lumpur, Malaysia \\ ${ }^{2}$ Dept. of Electrical Power, College of Engineering, Universiti Tenaga Nasional, \\ 43009 Kajang, Selangor, Malaysia \\ a) Muhamadm@uniten.edu.my
}

\begin{abstract}
This paper implements two main works. First, a new voltage-sag detection technique based on phase-angle analysis is proposed. It is simple to implement and able to detect and compensate sag the moment it occurs. Second, a new topology of voltage sag compensator is introduced. The proposed topology is able to reduce stress effect due to current flows into the switches and avoid non-stop operation during sag events. This proposed work had been verified and investigated by developing a laboratory prototype where a TMS320F2812 DSP is used as the main controller.
\end{abstract}

Keywords: voltage sag, voltage sag detection, voltage sag compensator

Classification: Electronic instrumentation and control

\section{References}

[1] Y.-S. Lee, H.-C. So, and M. H. L. Chow, "Design of AC Voltage Compensators," IPEMC, pp. 2587-2590, 2009.

[2] S. M. Deckmann and A. A. Ferreira, "About Voltage Sags and Swell Analysis, IEEE," pp. 144-148, 2002.

[3] K. Ding, K. W. E. Cheng, X. D. Xue, and B. P. Divakar, "A Novel Detection Method for Voltage Sags," 2nd Int. Conf. Power Electron. Syst. Appl., pp. 250-288, 2006.

[4] C. Hui-Yung, J. Hurng-Liahug, and H. Chieng-Lien, "Transient response of a peak voltage detector for sinuaoidal signals," IEEE Trans. Ind. Electron., vol. 39, pp. 74-79, 1992.

[5] A. A. Koolaiyan, A. Sheikhoeslami, and R. A. Kordkheili, "A Voltage Sag Compensation Utilizing Autotransformer Switched by Hysteresis Voltage Control," 5th Int. Conf. Electrical and Computer Engineering, Dhaka Bangladesh, pp. 545-550, Dec. 2008.

[6] R. Naidoo and P. Pillay, "A New Method of Voltage Sag and Swell Detection," IEEE Trans. Power Del., vol. 22, no. 2, April 2007.

[7] M. A. M. Radzi and N. A. Rahim, "Neural Network and Bandless Hys- 
teresis Approach to Control Switched Capacitor Active Power Filter for Reduction of Harmonics," IEEE Trans. Ind. Electron., vol. 56, no. 5, May 2009 .

\section{Introduction}

Sag detection is important as it determines the dynamic performance of a voltage-sag compensator. Many approaches have been introduced for voltagesag analysis and detection, for instance, RMS-Value Evaluation [1, 2, 3] and Peak-Value Evaluation [3, 4, 5], but unfortunately, most of them have a delay in detection and compensation time. The reliability of a voltage-sag compensator depends on the speed and preciseness of its detection technique, which should be able to determine the start and the end of voltage-sag occurrence. The duration of a voltage-sag is measured from the moment the RMS voltage drops to below $0.9 \mathrm{pu}$ of nominal voltage to when it rises to above $0.9 \mathrm{pu}$ of nominal voltage [6]. An ac voltage detector with a fast response characteristic is therefore needed to improve a system's transient performance. If response time can be reduced, transient performance can be improved [4], so immediate sag detection is vital.

This paper implements two main works. First, a new voltage-sag detection technique based on phase-angle analysis is proposed. The new technique is able to detect and compensate sag the moment it occurs. Beside fast detection response, it is simple to implement with less mathematical computation. Second, a new topology of voltage sag compensator is introduced. The proposed topology is able to reduce stress effect due to current flows into the switches and avoid non-stop operation during sag events. This proposed work had been verified and investigated by developing a laboratory prototype where a TMS320F2812 DSP is used as the main controller.

\section{Phase-angle analysis for voltage-sag detection}

RMS-value evaluation and peak-value evaluation take one cycle and at least a quarter of a cycle, respectively, to detect, and compensate voltage sag. This happens because the voltage controller used in the measurement needs the voltage-sag information for at least a quarter of a cycle.

The author finds that there is no necessity in retaining for some time, the voltage-sag information, as the following proves: Fig. 1 (a) represents the half cycle of a sinusoidal at normal voltage with peak value of $100 \mathrm{~V}$, and $90 \%$ $80 \%, 70 \%, 60 \%$, and $50 \%$ voltage sags. L6 is a vertical line intersecting at $90^{\circ}$ all the sinusoidal waveforms. The differences in voltage amplitudes among various voltage sags are clearly shown. L5, L4, L3, and L2 are vertical lines intersecting the sinusoidal waveform, at phase angles $72^{\circ}, 54^{\circ}, 36^{\circ}$, and $18^{\circ}$, respectively. From L5 to L2, the differences in voltage amplitudes for various voltage sags are also significant. Detection of voltage sag is thus observed to not need too much time in confirming the occurrence, or non-occurrence, 


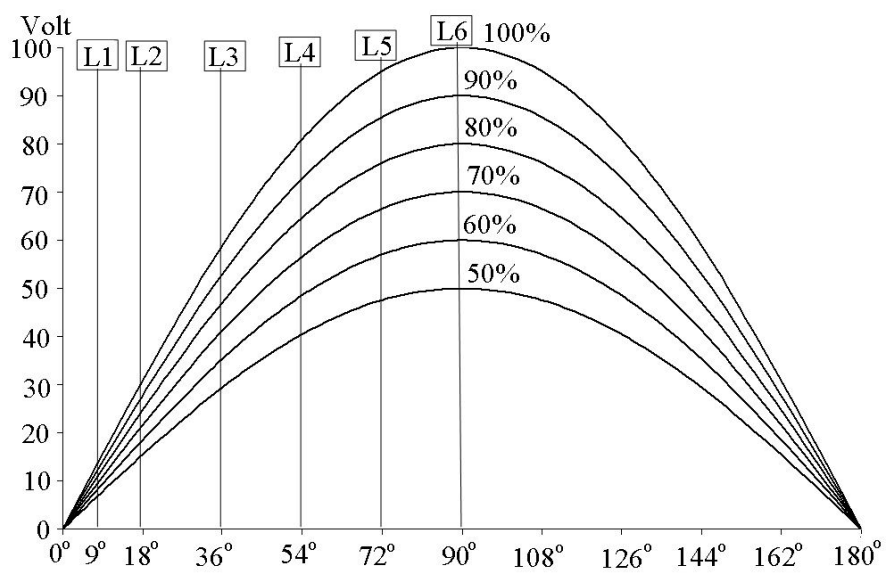

(a)

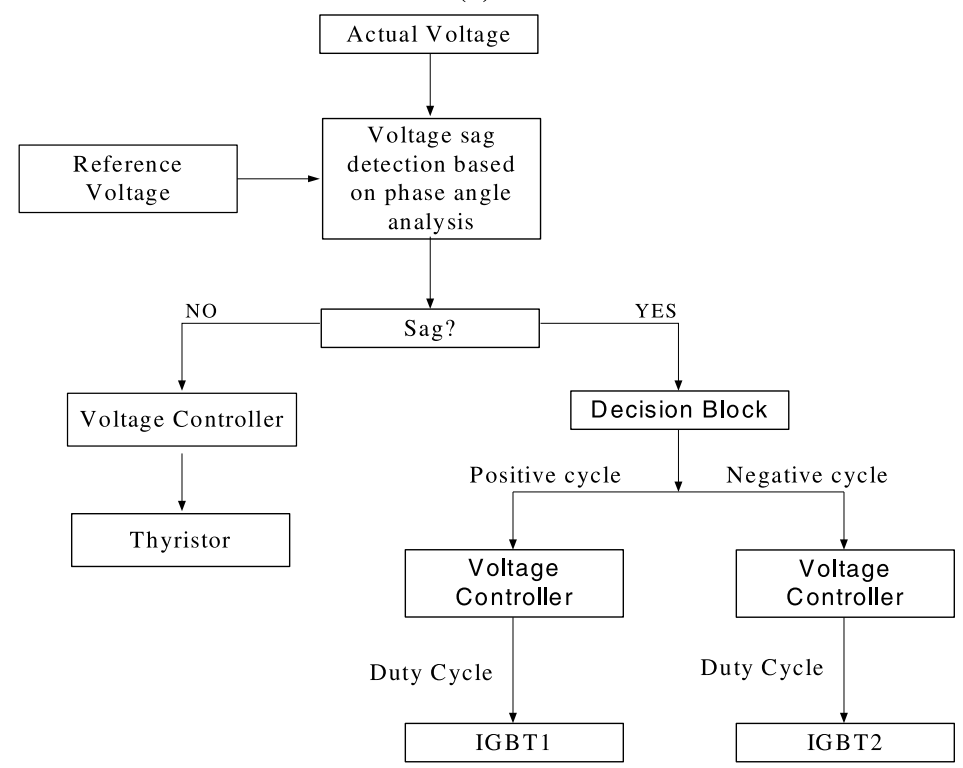

(b)

Fig. 1. (a) Half cycle of a sinusoidal at various voltage amplitudes (b) Flowchart of the new voltage sag detection technique

of the sag. The different voltage amplitudes of the voltage sags are also significant at $9^{\circ}$ phase angle. Therefore, information at $9^{\circ}$ is sufficient to indicate voltage sag. Determination of voltage amplitude is done by using [7],

$$
V(k)=V_{m} \sin (k w \Delta T)
$$

where $V(k)$ is voltage at sample $k, V_{m}$ is peak voltage, $k$ is sample in digital operation, $w$ is fundamental frequency, and $\Delta T$ is sampling time. For example, if sampling rate for one cycle of sinusoidal waveform is $k=200$, fundamental frequency is set at $50 \mathrm{~Hz}$ and $V_{m}=100 \mathrm{~V}$, then sampling time is calculated as,

$$
\Delta T=\frac{20 \times 10^{-3}}{200}=100 \mu \mathrm{s}
$$

Magnitude of normal voltage at $5^{\text {th }}$ sample, equivalent to $9^{\circ}$ phase angle, is 
calculated as follows:

$$
\begin{aligned}
& V(5)=100 \sin [(5)(2 \pi)(50)(100 \mu)] \\
& V=15.64 V
\end{aligned}
$$

If allowable voltage drop is less than $10 \%$, therefore voltage sag must be compensated if it drops to below $14.076 \mathrm{~V}$. Let's now calculate the magnitude of $70 \%$ voltage sag at the $5^{\text {th }}$ sample $\left(9^{\circ}\right)$, where $V m=70 \mathrm{~V}$,

$$
\begin{aligned}
V(5) & =70 \sin [(5)(2 \pi)(50)(100 \mu)] \\
& =10.95 \mathrm{~V}
\end{aligned}
$$

If (5) is compared with (4), the following is found:

$$
\frac{15.64-10.95}{15.64} \times 100 \%=30 \%
$$

meaning a voltage drop to $30 \%$ of rated voltage. This value is still the same with the percentage of voltage drop calculated at $90^{\circ}$ phase angle.

Fig. 1 (b) shows the process of the new voltage sag detection technique. Actual voltage is compared with reference voltage to determine whether sag occurs or not. If voltage sag is detected, the decision block will split the waveform into positive and negative cycles. Voltage controller will then produce a duty cycle, which will be utilized in producing PWM signal for the IGBT 1 and IGBT 2 while thyristor is turned OFF. If there is no voltage sag, voltage controller will produce gate signal for thyristor and command both IGBTs to turn OFF.

\section{Proposed voltage-sag compensator}

The proposed topology consists of one thyristor bypass switch and two bidirectional PWM insulated gate bipolar transistor (IGBT). This is to enable the IGBT1 to be in the OFF state during the negative cycle of sag and the IGBT 2 to be in the OFF state during the positive cycle of sag. Besides, IGBT1 and the IGBT2 will have less stress effect due to current where the input current flows in the circuit during voltage sag event will be equally divided. This will enhance the life span of both IGBTs. Fig. 2 shows the proposed voltage-sag compensator's topology. The compensator's working principle can be described as follows: During normal conditions, the bypass switch comprises a thyristor, remains ON while the IGBT1 and the IGBT 2 are OFF. If the sensing circuit detects more than $10 \%$ voltage sag, the bypass switch will be turned OFF by the voltage controller, which, at the same time, will command the IGBTs to start PWM switching so the output voltage is regulated and compensated back to normal voltage. Once the input voltage has no more sag or less than $10 \%$ sag, the voltage controller commands both IGBTs to turn OFF, turning the thyristor ON. The IGBT1 is only ON during positive cycle while the IGBT2 is turned ON during negative cycle. An autotransformer with ratio N1 : N2 = 1: 1 is used to boost up to $50 \%$ voltage sag. 


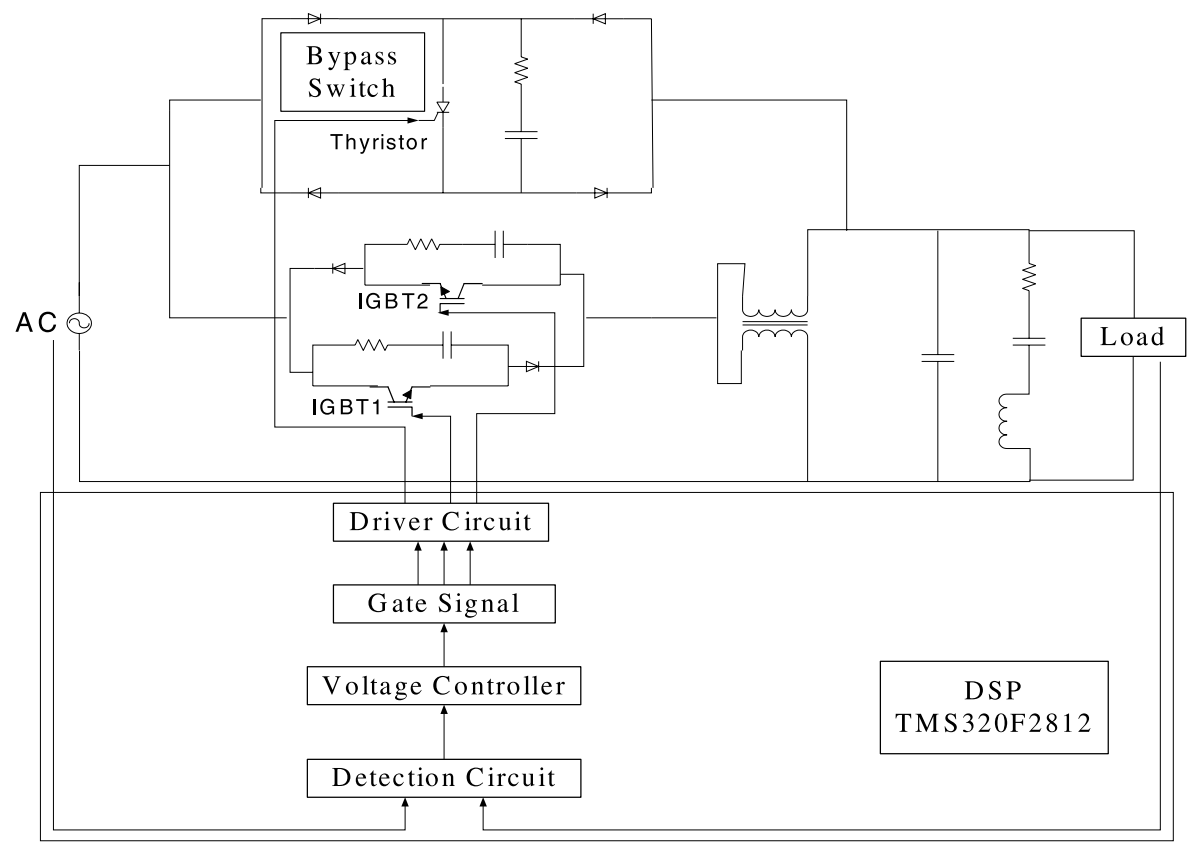

Fig. 2. Prototype setup of the proposed topology with a supply of 100 Vrms

\section{Experiment validation}

Figure 2 also shows a prototype developed to verify the validity of the proposed voltage sag detection technique and the proposed voltage sag compensator. A TMS320F2812 DSP was selected to implement the control algorithm as it has a 32-bits CPU performing at $150 \mathrm{MHz}$. Other interesting features of the TMS320F2812 DSP are its 12-b ADC module handling 16 channels and two on-chip event manager peripherals providing a broad range of functions particularly in control application.

An experiment has been carried out using 100 Vrms voltage. In digital control, data is based on sample time set through the controller [7]. This work used 200 samples per one cycle, for a $50 \mathrm{~Hz}$ operation. Sampling time is calculated as follows:

$$
\text { Sampling time }=\frac{T}{k}(s)
$$

Where $\mathrm{T}$ is time for one cycle and $\mathrm{k}$ is the number of samples in a cycle. Therefore, the sampling time used here is,

$$
\text { Sampling time }=\frac{20 m}{200}(s)=100 \mu s
$$

And sampling frequency $=\frac{1}{100 \mu}=10 \mathrm{kHz}$

The voltage feedback through voltage sensor input DSP with voltage amplitude and phase angle to enable the DSP to generate gate signals for the IGBTs and the thyristor. Gate signals are then transported to the switches through gate drive circuits. The switching frequency of the IGBT is $1.5 \mathrm{kHz}$. The thyristor gating pulse has a fixed pulse-duration, about 20 samplings, equivalent to $2 \mathrm{~ms}$. 


\section{Results}

Fig. 3 (a) and Fig. 3 (b) respectively show the input voltage, output voltage and the gate signals when $50 \%$ sag occurs at $0^{\circ}$ and $270^{\circ}$ phase angle. While Fig. $3(\mathrm{c})$ and (d) show voltage sag with phase jump. It is obviously shown that the output voltage is well regulated even though phase jump (circle in red) occur during the voltage sag. The IGBTs gate signals were observed to be produced by the DSP immediately the moment sag occurred. It also shows that the output voltage was well regulated compensated back to normal voltage the moment sag occurred without any difficulties and disturbances in the waveform.

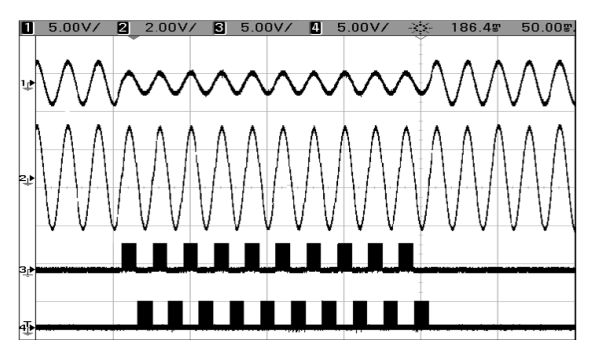

(a)

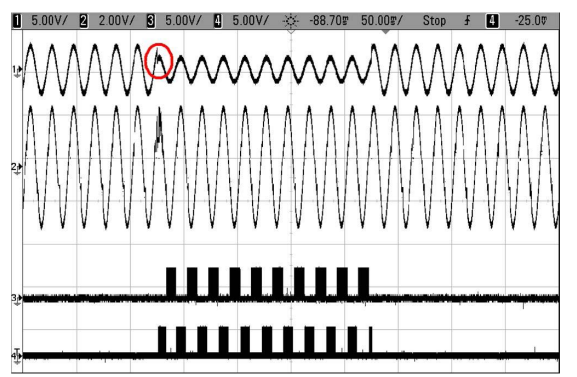

(c)

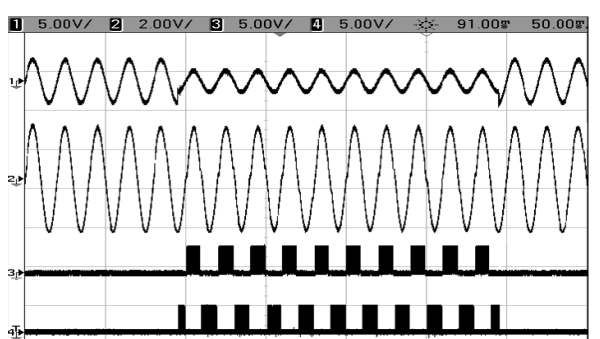

(b)

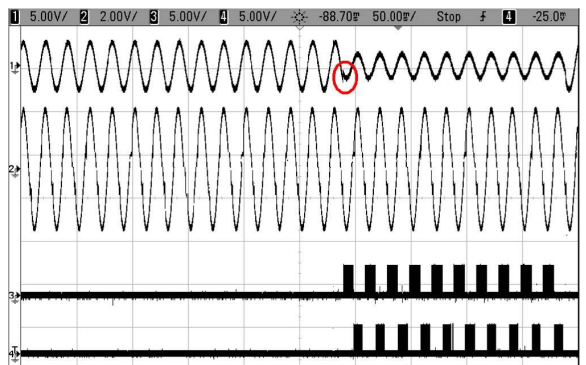

(d)

Fig. 3. Input voltage, output voltage and the gate signals when $50 \%$ sag occurs at (a) $0^{\circ}$ phase angle (b) $270^{\circ}$ phase angle (c) with phase jump (d) with phase jump

\section{Conclusion}

In this paper, a new voltage-sag detection technique based on phase-angle analysis and a new topology of voltage sag compensator has been presented. Results for voltage sags occur at four different phase angles show the effectiveness of the proposed control technique. The output voltage is compensated to normal voltage the moment sag occurs, without any disturbances to the output-voltage signal. The proposed voltage compensator has less stress effect due to current in the IGBTs to enhance the life span of IGBTs. The detection technique can be used to see a waveform's real-time variation from the ideal, and the sag's actual severity as well as the start and the end of sag. 